\title{
Measuring Phase Wave Velocity of Threads by Longitudinal Pulse Wave under Various Tensions
}

\author{
By Muneo Suematsu, Member, TMSJ \\ Faculty of Engineering, Gunma University, Kiryu
}

\begin{abstract}
This study discusses the loads and phase velocities of the longitudinal pulse waves of stress of several kinds of threads (raw silk, degummed silk, viscose rayon spun yarn and woolen yarn) under small tension.

An experiment by the author has shown that:

(1) The pulse velocity of a thread increases with an increase in tension. tension.

(2) Young's longitudinal modulus of a thread increases with an increase in

(3) The rate of increase in Young's longitudinal modulus for the load of spun yarns makes an exceedingly large value under weak tension of yarn.
\end{abstract}

\section{Introduction}

The filaments of textile fibers (raw silk, degummed silk, viscose rayon spun yarn and woolen yarn) are a uniform medium of elastic stress wave. There are published reports on experimental studies on the phase velocity, elastic modulus and internal friction of textile fibers. Those experiments have been made with the use of standing wave systems [1 6] or longitudinal wave systems $[4,5,7,8]$ and specimens of short lengths.

Spun yarns of textile fibers are constructed of short-length textile fibers and are not, therefore, a uniform medium of elastic stress wave. In the author's experiment, the two ends of yarn were fixed to a Rochell salt-receiving crystal. Then the phase velocity of isolated longitudinal pulse stress wave in the yarn was measured.

\section{Apparatus Used for Experiment}

There are published reports $[3,4,5,9]$ on apparatus to measure the propagation of elastic stress wave by cathode ray oscillograph. 'The author's experiment measured the relation between the tension and phase velocity of longitudinal pulse wave of spun yarn. Hence, the experiment was made by the method shown in Figure 1.

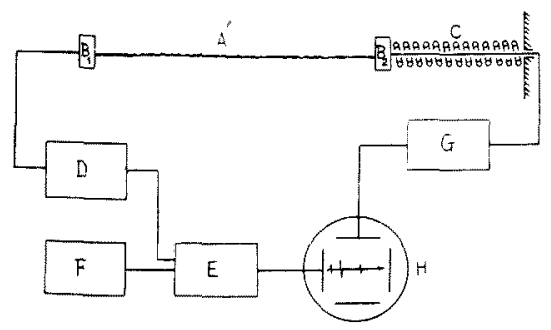

Fig. 1 Block diagram of experimental apparatus.
This figure shows the block diagram of the experimental apparatus used for the phase velocity of longitudinal elastic wave. $A$ is a test specimen. $B_{1}$ is the transmitter of a Rochell salt crystal. $B_{2}$ is the receiver of a Rochell salt crystal. $C$ is a spring balance. $D$ is a pulse generator of electric pulse waves (repeated period $=1 / 50 \mathrm{sec}$, pulse width $=10^{-4} \mathrm{sec}$ ). $E$ is the time-axis circuit of a cathode ray oscillograph. $F$ is a time mark generator driven by a quartz oscillator at $10^{4} \mathrm{c} / \mathrm{sec}$. $G$ is an amplifyer of pulse wave received by the receiver. $H$ is a cathode ray oscillograph.

\section{Method of Experiment}

The tension of yarn is measured by spring balance $C$. The phase velocity $v$ of pulse wave is calculated from

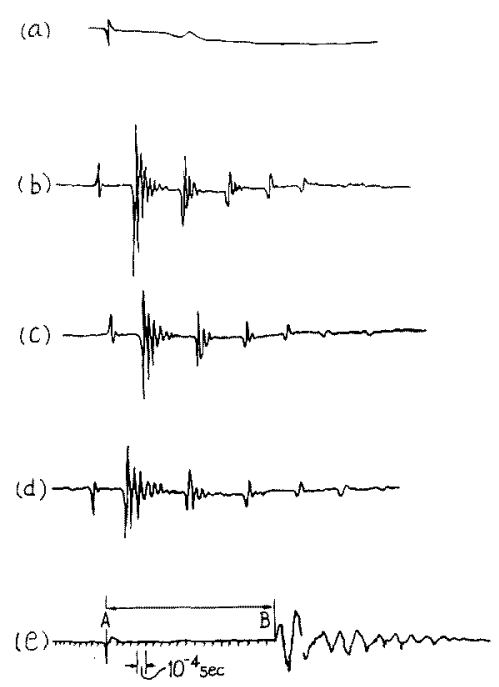

Fig. 2. Pulse propagation of several degrees of tension and time of travel of the pulse wave. 


$$
v=\frac{l}{t}
$$

where $l$ is the length of the specimen; and $t$ is the time of propagation from transmitting point $A$ to receiving point $B$ in Figure 2 (e).

\section{Results of Experiment}

\section{3-1. Phase Velocity}

The various specimens used and the conditions of the experiment are shown in Table 1. Threads differ from spun yarns in load and phase velocity curves of longitudinal pulse wave. The phase velocity of the longitudinal pulse wave of raw silk, degummed silk and nylon can be measured under tension as weak as $0.02 \mathrm{~g} / \mathrm{den}$ but the similar velocity of spun yarn cannot.

The curves (a), (b), (c) and (d) in Figure 2 show the relation between the pulse wave propagated in raw silk and the tension of raw silk. The curve (a) in Figure 2 shows the propaga-
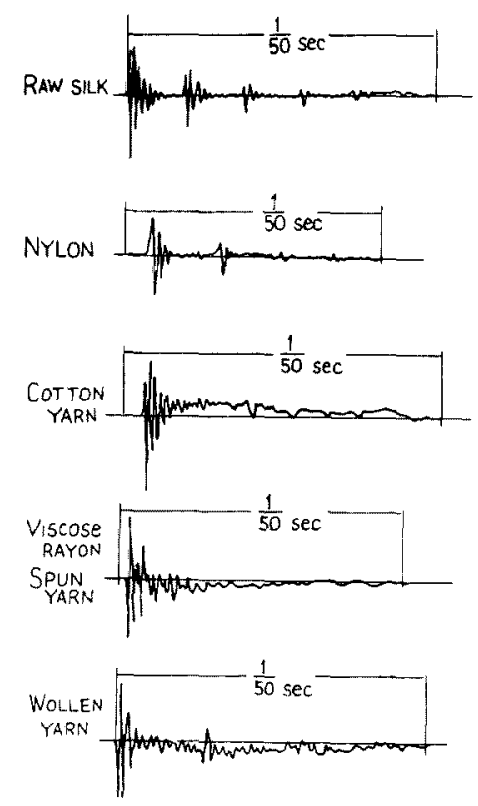

Fig. 3. Pulse propagation of several kinds of yarns under heavy tension. tion of pulse wave under a weak tension of 0.05 $\mathrm{g} / \mathrm{den}$, the curve (b), under a tension of $0.3 \mathrm{~g} /$ den, the curve (c), under a tension of $0.61 \mathrm{~g} / \mathrm{den}$, and the curve (d), under a tension of $0.93 \mathrm{~g} / \mathrm{den}$. Those curves clearly show repeated reflections of propagated longitudinal pulse waves.

Figure 3 shows the longitudinal pulse waves propagated in the several kinds of threads (raw silk, nylon, cotton yarn, viscose rayon spun yarn and woollen yarn) under heavy tension. In raw silk, the propagation of pulse wave of longitudinal stress wave clearly shows repeated reflections; in nylon, it shows repeated reflections accompanied by a weak noise. In cotton yarn and viscose rayon spun yarn, there are an irregular propagation, a heavy attenuation and, therefore, almost an absence of repeated reflections. In woollen yarn, there are an irregular propagation, a heavey attenuation and indistinct reflections.

It is specially to be noted the propagation of the longitudinal pulse stress wave of the longitudinal pulse stress wave of woollen yarn under weak tension is similar to the curve of the pulse stress wave of raw silk in Figure 2 (a), the wave form received being smooth and making a longer period.

The curves in Figure 4 show the load and phase velocity curves of the longitudinal pulse stress waves of several different yarns-including raw silk yarns of different twist numbers and degummed silk yarn. Confining attention to the raw silk yarns, we find that they are similar in

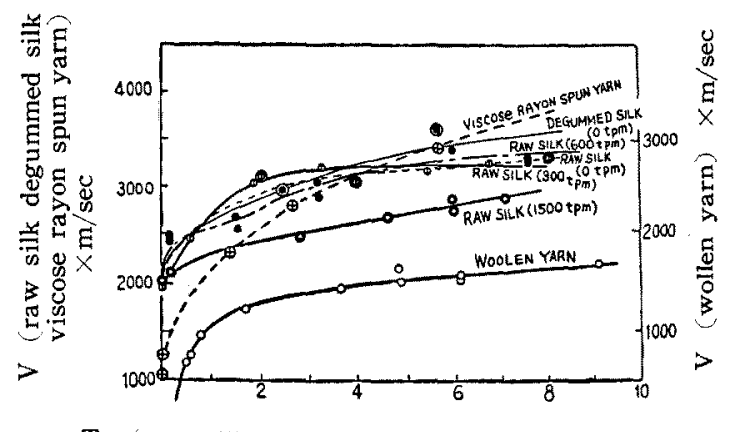

$\mathrm{T}$ (raw silk, degummed silk) $\times 10^{-1} \mathrm{~g} / \mathrm{den}$ (viscose rayon spun yarn, woollen yarn) $\times 100 \mathrm{~g}$

Fig. 4 Curves of load and phase velocity.

Table. 1 Sepecirmens and Conditions of Experiment.

\begin{tabular}{|c|c|c|c|c|c|c|c|}
\hline \multicolumn{4}{|c|}{ Specimen } & \multirow{2}{*}{$\begin{array}{l}\text { No, of twists } \\
\text { per meter }\end{array}$} & \multirow[b]{2}{*}{$\begin{array}{c}\text { Temperature } \\
\text { ( C) }\end{array}$} & \multirow[b]{2}{*}{$\begin{array}{r}\text { Humidity } \\
\text { (R.H.\%) }\end{array}$} & \multirow[b]{2}{*}{$\begin{array}{l}\text { Angular velocity } \\
\text { (radian/sec) }\end{array}$} \\
\hline Kind & Size & $\begin{array}{l}\text { Mass } \\
\text { (mg) }\end{array}$ & $\begin{array}{l}\text { Length } \\
(\mathrm{mm})\end{array}$ & & & & \\
\hline $\begin{array}{l}\text { Raw silk } \\
\text { Raw silk } \\
\text { Raw silk } \\
\text { Raw silk } \\
\text { Degummed silk } \\
\text { Visdose rayon }\end{array}$ & $\begin{array}{l}4 \times 21 \mathrm{D} \\
2 \times 4 \times 21 \mathrm{D} \\
2 \times 4 \times 21 \mathrm{D} \\
2 \times 4 \times 21 \mathrm{D} \\
4 \times 21 \mathrm{D}\end{array}$ & $\begin{array}{r}43.00 \\
94.12 \\
90.45 \\
101.02 \\
34.02\end{array}$ & $\begin{array}{l}5,000 \\
5,092 \\
5,043 \\
5,056 \\
4,995\end{array}$ & $\begin{array}{r}0 \\
300 \\
600 \\
1,500 \\
0\end{array}$ & $\begin{array}{l}19 \\
21 \\
18 \\
20 \\
17\end{array}$ & $\begin{array}{l}60 \\
70 \\
63.5 \\
60 \\
79\end{array}$ & $\begin{array}{c}18,849.5 \\
" \\
" 1 \\
\text { ", } \\
\text { " }\end{array}$ \\
\hline $\begin{array}{l}\text { supn yarn } \\
\text { Woollen yarn }\end{array}$ & $\begin{array}{l}2 \times 30 \text { 's } \\
2 \times 18 \text { 's }\end{array}$ & $\begin{array}{l}102.59 \\
217.12 \\
\end{array}$ & $\begin{array}{l}5,076 \\
5.082 \\
\end{array}$ & & $\begin{array}{l}18 \\
18\end{array}$ & $\begin{array}{l}63.5 \\
63.5\end{array}$ & " \\
\hline
\end{tabular}


form irrespective of the number of twists per meter and that their load and phase velocity curves are clustered, so to speak, in a small range.

The rate of increase in load and phase velocity curve in degummed silk is larger than in raw silk under every tension. The rate of increase of load and phase velocity curve in viscose rayon spun yarn is larger than in other yarns. The phase velocity of viscose rayon spun yarn varies from $1,000 \mathrm{~m} / \mathrm{sec}$ to $3,000 \mathrm{~m} / \mathrm{sec}$.

The rate of increase in the load and phase velocity curve of woollen yarn is a very large value under weak tension $(<0.625 \mathrm{~g} / \mathrm{den})$ but a small value under high tension $(1.8 \sim 3.6 \mathrm{~g} / \mathrm{den})$.

\section{3-2. Young's Longitudinal Modulus}

The fundamental equation connecting Young's modulus $E$ with the velocity $v$ of propagation of the stress pulse wave is

$$
v=\sqrt{\frac{E}{\rho}}
$$

where $\rho$ : density of fiber

The load and phase velocity curves of the longitudinal pulse waves of the several kinds of

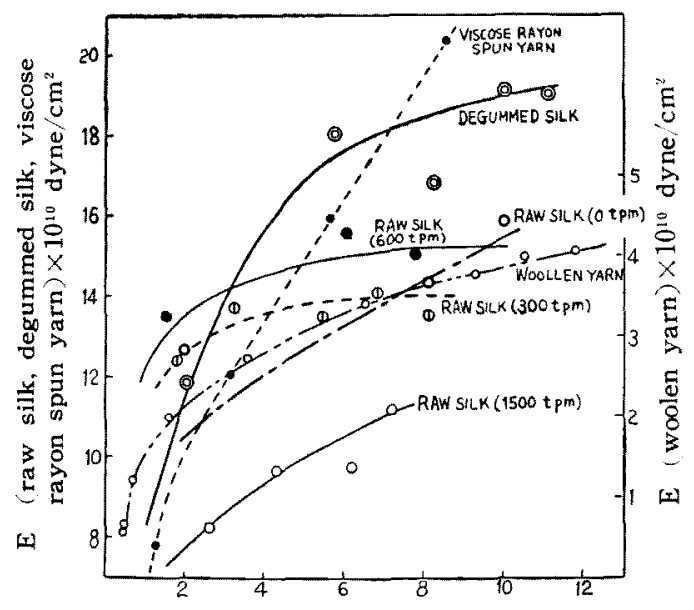

$\mathrm{T}$ (raw silk, degummed silk) $10^{-1} \mathrm{~g} / \mathrm{den}$ (viscose rayon spun parn, woollen yarn) $100 \mathrm{~g}$

Fig. 5 Curves of load and Young's longitudinal modulus. yarns in Figure 4 show that phase velocity is an increasing function of tension. The curves in Figure 5 show the load and Young's longitudinal modulus curves of the several kinds of yarns. Young's longitudinal modulus is calculated from equation (2); the phase velocities of yarns are given in Figure 4. It will be seen that the load and Young's longitudinal modulus curve of a yarn are similar to the load and phase velocity curve of longitudinal pulse wave of the same yarn.

\section{Conclusions}

(1) The phase velocities of the longitudinal pulse waves of spun yarns (viscose rayon spun yarn and woollen yarn) increase with tension. Particularly, the rate of increase in the phase velocity of spun yarn makes a large value under weak tension.

(2) The load and phase velocity curves of the longitudinal pulse waves of raw silk and degummed silk are similar in form, and are set near each other, irrespective of the number of twists per meter.

(3) The load and Young's modulus longitudinal curves of a yarn are similar in form to the load and phase velocity curves of the same yarn.

\section{Literature cited}

[1] J. W. Ballou. S. Silverman; J. Acous. Soc. Am., Vol. 16, p. 113 (1944)

2. A. W. Nolle; J. Acous. Soc. Am., Vol. 19, p. 194 (1947)

3. H. Kolskey; Stress Waves in Solids, Oxford Univ. Press, p. 141 (1953)

[4] N. Tokita; J. Japan Soc. Test. Material, Japanese edition, Vol. 2, p. 76 (1953)

[5] K. Fujino, H. Kawai, T. Horino, K. Miyamoto; J. Text. Mach. Soc., Japanese edition, Vol. 8, p. 98 (1955)

6 H. Tipton; J. Text. Inst., Vol. 56, T 322 (1955)

17 W. J. Hamburger; Private Communication.

(8) M. Chikin, N. H. Chanberlain; J. Text. Inst., Vol. 46, T 25 (1955)

[9] S. Takahashi; Electronician, Japanese adition, Vol. 1, p. 102 (1952) 